\title{
Lesbian womens' access to healthcare, experiences with and expectations towards GPs in German primary care
}

Oliver Hirsch", Karina Löltgen and Annette Becker

\begin{abstract}
Background: Lesbian women have higher rates of physical and psychiatric disorders associated with experiences of discrimination, homophobia and difficulties with coming out. Therefore, easy access to specialized healthcare in an open atmosphere is needed. We aimed to describe women's access to and experiences with healthcare in Germany, and to assess the responsibility of the general practitioner (GP) compared to other specialities providing primary health care.
\end{abstract}

Methods: A questionnaire study was conducted via internet and paper-based sampling. Using current literature, we designed a questionnaire consisting of sociodemographic data, sexual orientation, access to care and reasons for encounter, disclosure of sexual orientation, experience with the German health system (discrimination, homophobia), and psychological burden. Depression was assessed using the depression screening from the Patient Health Questionnaire (PHQ-2).

Results: We obtained responses from 766 lesbian women. Although $89 \%$ had a primary care physician, only $40 \%$ had revealed their sexual orientation to their doctor. The main medical contacts were GPs (66\%), gynaecologists (10\%) or psychiatrists (6\%). Twenty-three percent claimed they were unable to find a primary care physician. Another 12.4\% had experienced discrimination. Younger lesbian women with higher education levels and who were less likely to be out to other physicians were more likely to disclose their sexual orientation to their primary care physician. GPs play an important role in healthcare for lesbian women, even in a nongatekeeping healthcare system like Germany. Study participants suggested improvements regarding gender neutral language, flyers on homosexuality in waiting areas, involvement of partners, training of physicians, directories of homosexual physicians and labelling as a lesbian-friendly practice.

Conclusions: GPs should create an open atmosphere and acquire the respective knowledge to provide adequate treatment. Caring for marginal groups should be incorporated in medical training and further education. Ideally, physicians address patients' sexual orientation pro-actively in order to address individual needs accordingly.

Keywords: Female homosexuality, Health surveys, Internet, Questionnaires, Primary health care

\footnotetext{
* Correspondence: oliver.hirsch@staff.uni-marburg.de

Department of General Practice/Family Medicine, Philipps University

Marburg, Karl-von-Frisch-Str. 4, Marburg 35043, Germany
} 


\section{Background}

Several studies have shown that lesbian women have a higher rate of physical and psychiatric disorders than heterosexual women. Authors have found an increased risk for cardiovascular disorders and cancer, compared to non-lesbian women [1-3], and also for mood disorders, anxiety disorders, substance use and self-injuring or suicidal behaviour $[4,5]$. This seems to be associated with minority stress based on discrimination, homophobia and difficulties with coming out $[6,7]$. In a large survey at 33 health care sites in the USA, Koh and Ross found that lesbians who were not out were 2-2.5 times more likely to have had suicidal thoughts during the past year. A suicide attempt occurred more often in lesbians and bisexual women who were not out compared to heterosexual women [8].

The aforementioned studies highlight the need for improvements in healthcare provision for lesbian women, especially in primary care, which is usually the first area of contact with the healthcare system. Several factors have been shown to positively influence healthcare provision for these women: The more lesbian women are comfortable with their sexual identity, the better the healthcare provision. This may be because disclosure in the medical context seems much easier for people confident about their sexual identity. Furthermore, the better the integration in their social environment, the more comprehensive their coming out, which leads to a higher openness to physicians who in turn are then better able to adapt to their needs [9].

Another important point is the physicians' behaviour during the consultation. Physicians have no special qualification for treating homosexual patients. Discrimination, homophobia, and lack of attention regarding gender neutral language have been observed [10, 11]. Recommendations for different medical contexts like primary care, mental health, oncology, and public health are available [4, 12-16]. However, there is still a lack of training resources [16], and the special needs of LGBT (Lesbian, Gay, Bisexual, Transgender) patients are neglected worldwide. On the one hand, GPs and medical students in Ireland do not feel prepared to deal with sexual health issues in lesbian, gay and bisexual patients because they do not possess the required communication skills to competently interact with non-heterosexual patients, as shown in a qualitative study by Stott et al. [17]. On the other hand, LGBT patients want their health providers to be more aware of their health needs. Lesbian and bisexual women in the Cape Town area of South Africa experienced verbal discrimination, especially in public care [18]. In another qualitative study undertaken in Portugal, lesbian women also expressed their demand for a better training of healthcare professionals regarding homosexual issues. Participants suggested that healthcare providers should not show signs of disapproval when a lesbian woman outs herself, they should not assume that all women are heterosexual, and they should provide interventions tailored to the specific needs and interests of lesbian women. The results of the study further showed that a guarantee of confidentiality would have encouraged the interviewed women to disclose their sexual orientation to their physician [19].

The aforementioned requests and conclusions highlight that there are special healthcare needs among lesbian women, but appropriate supportive care is not the norm. Current research worldwide suggests that lesbian women's particular health needs are neglected, so the question arises whether the same holds true in Germany. Studies on lesbian health in Germany are rare. Most of the available data originates from the USA, where the healthcare system is fundamentally different and therefore not necessarily comparable. It is estimated that between 0.4 and $1.3 \%$ of German women are exclusively homosexual [20]. The German Federal Statistical Office mentions in its 2010 microcensus that 27000 women live together in same-sex partnerships, 10000 of which are officially registered.

In Germany, primary care physicians are not gatekeepers. Patients have direct access to primary and secondary care specialists, with approximately half of all office-based physicians being GPs. The aim of our study was to examine the lesbian women's preferred access paths to medical care (GP or specialist) in order to clarify GPs role in caring for these women. We assessed lesbian women's experiences with and desires regarding medical providers. The questions are: Who are lesbian women's preferred contact persons in the nongatekeeping health care system of Germany and what are their reasons for encounter? How do lesbian women experience primary care providers (e.g. use of gender neutral language, asking for sexual orientation) and to what extent have they been confronted with discriminating behaviour within the German health care system? What are predictors for women disclosing their sexual orientation towards their GP? What desires or ideas for improvement do lesbian women express in connection with their healthcare provision?

\section{Methods}

\section{Questionnaire}

Using current literature, we designed a questionnaire consisting of sociodemographic data (age, residence, secondary education level, professional education, employment status, monthly income, marital status, living with partner and being a parent or co-parent), sexual orientation, access to care (specialist or GP), health care utilisation during the previous 12 months and reasons for encounter (see Additional file 1). Furthermore, we 
included questions on disclosure of sexual orientation, experience with the German health system (discrimination, homophobia), and psychological burden. Some survey questions were developed by the research team, while those examining depression and discrimination experiences drew on existing instruments [21, 22]. Disclosure of sexual orientation in the private context was examined with the question "Have you disclosed your sexual orientation? If yes, to whom?" Possible answers were: "No disclosure; Just to close friends; Just to family of origin; Just to close friends and family of origin; Comprehensive disclosure (family, friends, colleagues)". We also asked if the participants were out to their main medical contact person (yes/no).

To measure discrimination experiences we included five questions to be answered "yes" or "no": "Have you ever refrained from a necessary examination or treatment because you were afraid of being discriminated because of your sexual orientation?", "Have you ever felt discriminated against by physicians, in hospitals or in other areas of the healthcare system because of your sexual orientation?", "Have you ever been refused an examination or treatment because of your sexual orientation?", "Have you ever felt that your physician should know about your sexual orientation prior to an examination or treatment, but you did not disclose it for fear of negative consequences?", and "Did you ever feel the need to talk about your sexual orientation with your medical contact person, but he/she dismissed it?" [23-25].

Depression was assessed using the depression screening from the Patient Health Questionnaire (PHQ-2) consisting of two items on a four point scale ( $0-3$ points) $[21,22]$. It has a maximum score of six points and a cutoff value ( $\geq 3$ points) leads to a suspected diagnosis of a depressive episode. It has been adapted and validated in the German context [22]. The German version has an internal consistency of $\alpha=.83$, a sensitivity of $87 \%$ and a specificity of $78 \%$ for major depressive disorder, and it proved sensitive to change. Kroenke et al. have also shown the construct and criterion validity of this instrument [21]. The women were asked whether they were impaired because of further psychological symptoms in the past four weeks, for example regarding sudden feelings of fear and panic (yes/no).

Information on suggestions for improvement in connection with health care provision was collected by a multiple choice question with selected answers based on current literature [26, 27]. Women were asked to select four of twelve proposed improvements (e.g. gender neutral language, special training of physicians, flyers on homosexuality in waiting area, labelling as LGBT friendly practice). Besides they had the opportunity for free text responses.
A pilot study with subsequent adaptation of the questionnaire was performed with 18 lesbian women. It consisted of seven pages and took approximately ten minutes to complete.

\section{Study design}

Women had to be 18 years or older and to identify themselves as a lesbian to be included in the study.

To achieve a high probability of external validity we chose different sampling strategies including different strategies of personal recruitment and using the internet. The internet-based sample was recruited via www.lesarion.de, one of the largest Internet information and dating platforms for lesbian women. A thread called 'Study for lesbian women' was created on the bulletin board with a link to the questionnaire on https://www.limesurvey.org/de/, a platform for online surveys. A banner advertisement on the homepage of http://de.lesarion.com/ was used to advertise for the study. Potential participants received written information stating that the study aimed to collect data on healthcare provision for lesbian women in Germany and help to improve the latter. By clicking a verification button, women expressed their informed consent and were able to access the questionnaire. Participants received no financial incentive. Data collection lasted for seven days in June 2011 and resulted in 272 participants.

The paper-based sample was recruited in Cologne and Frankfurt and generally relied on snowball sampling. Recruitment took place at the respective Christopher Street Day Celebrations in 2011, at lesbian counselling centres, self-help groups, private gatherings and reading events. The Christopher Street Day is an annual celebration and demonstration held in different cities in Europe in memory of the first uprisings of LGBT people against police assaults in New York City. Participants were personally contacted by one of the authors (CL). They were informed about the study by a leaflet that contained the same study information offered online and were asked to complete the questionnaire after giving their verbal informed consent. Participants received no financial incentive. The data collection lasted from May to September 2011.

The study was approved by the local medical ethics committee of the Department of Medicine at Philipps University Marburg, Germany with reference number 06/11.

\section{Statistical methods}

Descriptive statistics were used to analyse responses to questionnaire items and to describe women's access to health care (preferred contact person, reason for encounter) as well as experiences within the health care system, and suggestions for further improvement. Associations between certain attributes were examined using Spearman's rho. We applied logistic regression analysis 
[28] to predict disclosure to the GP (yes/no) by age, education, time since outing (less than 12 months, 1 to 5 years, more than 5 years), discrimination experience (dichotomous; at least one "yes" response in the five questions on discrimination lead to coding "yes"), further need for provision of medical service because of sexual orientation (yes/no), and comprehensive disclosure to other physicians (yes/no). We decided not to use a stepwise approach since we had no a priori hypotheses about which variables might best separate the groups, and stepwise methods use only data-driven criteria and are therefore regarded as controversial [29]. Several tests and indices were used to assess model fit: $-2 \log$ likelihood test, Hosmer-Lemeshow-Test, deviance measure, likelihood ratio tests for predictors; pseudo-R-squares: Cox and Snell, Nagelkerke and McFadden; and correct classification rates [29].

\section{Results}

\section{Demographic characteristics}

We obtained responses from 766 lesbian women living in Germany. They were all German citizens. Altogether, 494 lesbian women participated in the paper-based sample, evenly distributed between the two locations.

The resulting dataset was checked for duplicates to ensure that no one was recruited in both samples. For this, we sorted the dataset according to demographic characteristics and looked for identical patterns. No duplicates were found. In a different publication we were able to show that the paper-based and Internet-based samples did not differ substantially [30]. We asked for the demographic characteristics of age, sexual orientation, residence, secondary education level, professional education, employment status, monthly income, marital status, living with partner and being a parent or co-parent. They are depicted in Table 1.

The mean age of the sample was 32.5 years (SD 9.6). The vast majority was exclusively or mainly homosexual. Their place of residence was evenly distributed between major and small towns, with a minority living in the countryside. Levels of graduation and professional education were relatively high. The proportion of unemployment among respondents was considerably higher than the unemployment rate in Germany (17.5\% vs. $7 \%)$. About one third of the sample had a low income of up to 1000 Euro per month. About half of the women were in a relationship, but only one third were living together with their partner. Merely $13.6 \%$ were in the position of being a parent or co-parent.

\section{Lesbian women's preferences regarding primary care physicians and reasons for encounter}

Approximately $68.7 \%$ of the interviewed women stated that they discuss results from secondary care (e.g.
Table 1 Demographic characteristics of our lesbian sample $(n=766)$

\begin{tabular}{|c|c|}
\hline Mean age & 32.5 (SD 9.6); range 18-67 \\
\hline \multicolumn{2}{|l|}{ Sexual behavior } \\
\hline exclusively or mainly homosexual & $89.9 \%$ \\
\hline equally homo- and heterosexual & $7.5 \%$ \\
\hline mainly heterosexual & $1.4 \%$ \\
\hline heterosexual & $1.2 \%$ \\
\hline \multicolumn{2}{|l|}{ Residence } \\
\hline major town & $46.5 \%$ \\
\hline small town & $39.2 \%$ \\
\hline countryside & $14.3 \%$ \\
\hline \multicolumn{2}{|l|}{ Secondary education level } \\
\hline low & $7.1 \%$ \\
\hline medium & $31.6 \%$ \\
\hline high & $61.3 \%$ \\
\hline \multicolumn{2}{|l|}{ Professional education } \\
\hline apprenticeship & $34.3 \%$ \\
\hline school-based & $16.6 \%$ \\
\hline university & $32.1 \%$ \\
\hline other & $5.2 \%$ \\
\hline none & $11.8 \%$ \\
\hline \multicolumn{2}{|l|}{ Employed } \\
\hline yes & $82.5 \%$ \\
\hline no & $17.5 \%$ \\
\hline \multicolumn{2}{|l|}{ Monthly income } \\
\hline$<400 €$ & $9.4 \%$ \\
\hline $401-1000 €$ & $18.4 \%$ \\
\hline $1001-4000 €$ & $58.2 \%$ \\
\hline$>4000 €$ & $8.2 \%$ \\
\hline none & $5.8 \%$ \\
\hline \multicolumn{2}{|l|}{ Marital status } \\
\hline single & $42.2 \%$ \\
\hline in relationship & $55.5 \%$ \\
\hline divorced/widowed & $2.3 \%$ \\
\hline \multicolumn{2}{|l|}{ Living with partner } \\
\hline yes & $30.1 \%$ \\
\hline no & $69.9 \%$ \\
\hline \multicolumn{2}{|l|}{ Parent/co-parent } \\
\hline yes & $13.6 \%$ \\
\hline no & $86.4 \%$ \\
\hline
\end{tabular}

cardiologist, neurologist, etc.) with their GP. The main medical contact person was the GP in $66.3 \%$ of respondents, the gynaecologist in $10.6 \%$ and a psychiatrist in $5.5 \%$. Additionally, $12.3 \%$ of respondents did not have a main medical contact person and were not actively looking for one; $2.0 \%$ named other medical facilities, and 3.3\% 
provided no data. A female physician was favoured by $26.4 \%, 69.3 \%$ had no preference, $3.9 \%$ favoured a male physician, and $0.4 \%$ did not answer this question. Twentytwo point eight percent were actively looking for a main medical contact person but were unable to find one. A slightly larger proportion of respondents (45.4\%) were out to their gynaecologist compared to their GP (39.2\%). In the previous 12 months, most of the women consulted a physician because of an acute illness (76.6\%), 50.5\% for preventive measures, $22.7 \%$ because of psychological symptoms, $20.5 \%$ because of a chronic disease, and $4.8 \%$ for counselling, e.g. to quit smoking. Over-the-counter drugs were taken regularly by $8.7 \%$, prescription drugs by $25.8 \%$. A majority of the women has regular contact with their GP (74.4\%), 54.0\% have regular contact with a gynaecologist, $21.0 \%$ with a psychiatrist and $29.1 \%$ with other physicians. Preventive medical check-ups were attended by $83.6 \%$; details are listed in Table 2 .

\section{Women's experiences within the healthcare system}

Only a minority of lesbian women in this study (5.2\%) reported being directly asked about sexual orientation by a healthcare provider. Knowledge regarding lesbianspecific issues in physicians was judged positively by $21.5 \%$ of lesbian women, $14.5 \%$ were satisfied but saw room for improvement, 9.8\% said that only basic knowledge was available, $3.1 \%$ stated that no lesbian specific knowledge was present, $50.5 \%$ said that they were unable to rate this knowledge, and $0.5 \%$ did not answer this question.

Not having attended a necessary examination or treatment because of feared discrimination was reported by $7.7 \%, 12.4 \%$ had experienced discrimination in the German healthcare system, 3.8\% were denied an examination or treatment because of their sexual orientation, $11.9 \%$ did not disclose their sexual orientation to physicians although it was important for examination or treatment, and $16.4 \%$ felt the need to talk about their sexual orientation and were not taken seriously by medical personnel. It is well-established that discrimination experience is associated with depressive symptoms [31]. In our

Table 2 Percentages of lesbian women attending preventive medical check-ups

\begin{tabular}{ll}
\hline Medical faculty & $\%$ \\
\hline gynaecology & \\
(at least one preventive check-up) & 74.1 \\
mammography & 13.7 \\
pap smear & 56.1 \\
dentist & 76.8 \\
vaccination & 46.2 \\
colon cancer screening & 5.7 \\
\hline
\end{tabular}

sample, discrimination experience was not significantly correlated to depression (PHQ-2; rho $=.01, p=.82$ ). In our sample, $7.7 \%$ reported clinically-relevant depressive symptoms, and $17.1 \%$ mentioned that they had experienced a panic attack in the previous four weeks. The mean score in the PHQ-2 (1.4, SD 1.4) was not different from a healthy control group [22].

\section{Predictors of disclosure of sexual orientation towards the GP}

In our sample, $87.9 \%$ reported having a primary care provider (resident specialist or GP); however, $60.6 \%$ of these respondents had not informed their primary care provider about their sexual orientation. Altogether, $47.8 \%$ stated that their main medical contact person was informed about their sexual orientation. For those claiming to have a GP as primary care physician we used logistic regression to predict disclosure to the GP (yes/ no) as there is evidence that such a disclosure had a positive impact on healthcare provision for lesbian women. No multicollinearity was present as all variance inflation factors were around 1 and therefore much lower than the critical cut-off of 10 [29]. The likelihood ratio test resulted in three significant predictors after adjusting for multiple testing $(p=.05 / 6=.008)$ as a test is performed for each predictor separately [28]: age, education and disclosure to other physicians (Table 3). Those with a younger age, a higher formal education and who were not out to other physicians were more likely to have disclosed their sexual orientation to their GP. The overall correct classification rate was $70.9 \%$ and consequently unsatisfactory. Compared to the interceptonly model, our model demonstrated a significant improvement in the $-2 \log$ likelihood test $\left(\chi^{2}(\mathrm{df}=6)=\right.$ 165.62, $p<.001)$. The Pearson deviance measure, as a goodness-of-fit statistic comparing observed with expected frequencies, showed a good fit $\left(\chi^{2}(\mathrm{df}=472)=\right.$ 463.99, $p=.60$ ). The Hosmer-Lemeshow-Test which is based on a similar approach also shows a good model fit $\left(\chi^{2}(\mathrm{df}=8)=3.25, p=.92\right)$. The following effect size values occurred: McFadden's $\rho^{2}=.18$, Cox and Snell Pseudo- $R^{2}$ $=.20$, and Nagelkerke Pseudo- $R^{2}=.27$. McFadden's $\rho^{2}$ was just under the recommended cut-off of .2 [29], while the other two effect sizes signaled acceptable proportions of explained variance.

\section{Areas for improvement}

Lesbian women in our study were asked to consider ways to improve interactions with health professionals. These are depicted in Table 4.

Unfulfilled global healthcare needs were expressed by $25.6 \%, 9.5 \%$ had general medical requests, $2.6 \%$ would like to get access to lesbian information centres, $3.8 \%$ would like to receive more information on sexually 
Table 3 Predictors of disclosure of sexual orientation to primary care physicians: Results of the logistic regression analysis

\begin{tabular}{lllll}
\hline & $\mathrm{B}$ & Likelihood Ratio Test $x^{2}(\mathrm{df}=1)$ & Significance $p$ & Odds Ratio (95\% confidence interval) \\
\hline Disclosure to other physicians & -1.83 & 92.24 & $<.001$ & $0.16(0.11-0.23)$ \\
Age & -.03 & 10.62 & .001 & $0.97(0.95-0.99)$ \\
Education & .40 & 8.83 & .003 & $1.50(1.15-1.96)$ \\
Time since outing & -.36 & 5.00 & .024 & $0.70(0.51-0.96)$ \\
Further need of medical service & .15 & 0.59 & .44 & $1.16(0.80-1.68)$ \\
Discrimination experience & .09 & 0.22 & .64 & $1.09(0.76-1.57)$ \\
\hline
\end{tabular}

Significant predictors after Bonferroni correction printed in bold

transmitted diseases, and $12.9 \%$ would like to discuss their desire for children. A request for special care because of their sexual orientation was expressed by $30.9 \%$.

\section{Discussion}

Given the evidence of an increased morbidity of lesbian women compared to their heterosexual counterparts [1-4], we conducted a survey on lesbian women's access to German healthcare to learn about their experiences with and expectations towards primary care physicians. The aim of the study was to clarify the GPs' role in caring for homosexual women in a non-gatekeeping healthcare system. We received responses from 766 women. The majority of women had regular contacts with their GP and gynaecologist, and two-thirds of them named the primary care physician as their main medical contact person from whom they seek care for acute and chronic illnesses, and discuss results from secondary care, and for non-gynaecological prevention. More than 20\% of women had looked for a trustworthy person in health matters without finding one. Experiences or fear of discrimination were reported by $12 \%$ of the women. Disclosure of sexual orientation was not pursued by $40 \%$ of women, $12 \%$ of whom stated this was for fear of negative

Table 4 Percentages of lesbian women proposing specific improvements

\begin{tabular}{ll}
\hline Area & $\%$ \\
\hline gender neutral language & 36.7 \\
flyers on homosexuality in waiting area & 29.8 \\
involvement of partner & 29.4 \\
training of physicians & 27.4 \\
directory of homosexual physicians & 24.7 \\
labelling as lesbian friendly practice & 24.4 \\
more homosexual physicians & 18.8 \\
direct question regarding sexual orientation & 16.4 \\
support disclosure & 14.9 \\
provide lesbian specific information & 14.8 \\
consultation hours for lesbians & 8.7 \\
physician should ask regarding social integration & 8.2 \\
\hline
\end{tabular}

consequences, even though they deemed this information useful for medical care planning.

Our study showed that in a non-gatekeeping system like Germany, GPs still play a decisive role in caring for lesbian women. In our study sample every second women sees a gynaecologist on a regular basis, mostly for gynaecological prevention, the most frequently accessed preventive service (by 70\% of participating women). However, GPs remain the main contact persons for healthcare needs. This corresponds with GPs' function as coordinator in healthcare, providing a comprehensive and general approach to medicine. The findings highlight a need among GPs to foster a deeper knowledge and awareness of problems associated with homosexuality. There is no doubt that women concealing their sexual preference and GPs ignoring this part of patients' life risk missing appropriate actions, including preventive services or referrals [32-34]. About 20\% of the women in our study reported psychological symptoms as reason for encounter, but bio-psycho-social counselling may not be effective when women avoid disclosing their sexual orientation [35]. In our study more women disclosed to their gynaecologist than to their GP and only $5 \%$ were directly asked about their sexual orientation by the physician. It may be that physicians do not recognize the information's relevance for nongynaecological health issues and that disclosure to a gynaecologist is easier because it seems to be more obvious to discuss sexual issues in this context of health care than for example with a GP.

There is one other similar study in Germany by Dennert et al. who obtained quantitative data from 578 lesbian women attending a special spring meeting in Cologne. Similar to our study, the authors found that half of the respondents had not informed their primary care providers about their sexual orientation, and indeed preventive measure in the study sample were less frequent than in a representative sample of the gender population [36, 37]. Disclosure is of particular importance in primary care for the detection of healthcare needs and tailoring of treatment. We therefore aimed to identify factors associated with disclosure to GPs: Young age, a higher educational level and those who are not 
out to other physicians were more likely to reveal their sexual orientation to their primary care physician. We found no significant association between disclosure to primary care providers and the time since outing or previous discrimination experiences. Our results are in line with other studies that confirmed the influence of education as a predictor of disclosure [35]. Additionally, St. Pierre et al. found a positive association between higher income and disclosure of sexual orientation to primary care providers [38]. Other predictors for a higher probability of disclosure from different studies are: less internalized homophobia, a stronger connection to the LGBT community, not having an immigration status, not having a history of a medical condition, a higher provider's gay-positivity and a higher level of the patient's outness [10]. All studies show methodological limitations and the included factors overlap only marginally between studies, which impedes the distinction between real effects, confounding or setting specific phenomena.

A positive interpretation of the observed association between young age and disclosure in our study could suggest that societal changes towards less stigmatization and more tolerance favourably affect younger lesbians' perception of healthcare. In the United States, there has been improved utilization of preventative services among lesbian women, as described by Roberts et al. [39], but a recent report by the European Union Agency for Fundamental Rights (FRA) highlights frequent ongoing discrimination and violence against lesbian, gay, bisexual and transgender individuals in all member states, including Germany [40].

Discrimination of lesbian women in German healthcare has only begun to be studied. We found that $12 \%$ of participants did not share their sexual orientation with their GP for fear of negative consequences, even though they deemed this information useful for medical care planning. Twelve percent of participants had also experienced discrimination in the past. The only other study on discrimination experiences in German healthcare found a corresponding rate of $20 \%$, where $20 \%$ also did not share their sexual orientation with any physician (any speciality) [37].

Awareness of lesbian health needs and initiatives for improvement seem to fall behind in Germany compared to Anglo-American countries, where position papers and recommendations have been published to advise on special healthcare needs and the avoidance of discriminating behaviour [27, 41]. A comparable statement for Germany does not yet exist, even though there is evidence of perceived barriers to healthcare among lesbian women. When asked for their suggested areas for improvement, women participating in our study named gender neutral language, flyers on homosexuality in the waiting area, involvement of a spouse, training of physicians, a directory of homosexual physicians, and labelling as a lesbian-friendly practice. There have been interventions claiming to alleviate these problems, but to our knowledge there is no evidence showing their effectiveness. Innovative treatment and service programs tailored to address the specific needs of sexual minority groups should be developed, implemented and evaluated [42]. According to Kerr et al., healthcare providers should undergo diversity and sensitivity training to work more effectively with these groups, and physicians should inquire about the sexual orientation of their patients [43].

There are limitations to our study. We applied convenience sampling, which is a debatable method [44], but it is still an acknowledged technique for reaching underrepresented populations [45]. Research in lesbian health is largely based on self-recruited or conveniencebased samples. This poses problems regarding the generalisation of results depending on the study's aim [46]. Our samples (internet based and at special events) may be biased, but the described similarities of study results with national and international studies suggest a reasonable external validity. Convenience-based sampling can produce valuable results [47]. We therefore hope our results will stimulate further research.

We compared internet- and paper-based samples of lesbian women in Germany and found neither statistically significant nor content-relevant differences between the two groups [30]. Data merging therefore seems justifiable. Similar approaches have been chosen by studies in different contexts [48]. When interpreting our healthcare utilization data, one needs to consider that we relied on self-report measures, which tend to overestimate participation rates in preventive health screenings [49], whereas issues concerning mental health (as a sensitive topic) are most likely underestimated [8].

Our findings might be biased giving the sociodemographic profile of our respondents as our sample were predominantly young and well educated.

\section{Conclusions}

We conclude that our findings on lesbian women's access to healthcare and their expectations towards primary care physicians in Germany highlight the considerable responsibility of the GP (even in a nongatekeeping healthcare system). It is up to the GPs to create an open atmosphere and to acquire the respective knowledge to provide adequate treatment. Caring for marginal groups should be incorporated in medical training and further education. Furthermore it may be prudent to promote a management approach to healthcare, where physicians address patients' sexual orientation pro-actively in order to address individual needs accordingly. 


\section{Additional file}

Additional file 1: Study Questionnaire. English translation of the items used in the study. (DOCX $84 \mathrm{~kb}$ )

\section{Abbreviations}

Df: Degrees of freedom; FRA: European Union Agency for Fundamental Rights; GP: General practitioner; LGBT: Lesbian, gay, bisexual, transgender; PHQ-2: Patient health questionnaire

\section{Acknowledgements}

None.

\section{Funding}

No funding was obtained.

\section{Availability of data and materials}

The data will not be made available in order to protect the participants identity.

\section{Authors' contributions}

$A B$ conceived of the study, participated in the design and in the interpretation of the data, and helped to draft the manuscript. $K L$ conceived of the study, participated in the design, collected the data and helped to draft the manuscript. $\mathrm{OH}$ drafted the manuscript, performed the statistical analyses and interpreted the data. All authors read and approved the final version of the manuscript.

\section{Authors' information}

Annette Becker is a Professor and Oliver Hirsch is a Senior Research Fellow at the Department of General Practice/Family Medicine at Marburg University. Karina Löltgen is a Doctoral student at the Department of General Practice/ Family Medicine at Marburg University. Annette Becker is a practicing family physician.

\section{Competing interests}

The authors declare that they have no competing interests.

\section{Consent for publication}

Not applicable.

\section{Ethics approval and consent to participate}

The study was approved by the local ethics committee of the Department of Medicine at Philipps University Marburg, Germany with reference number 06/11. Potential participants in the online study received written information stating that the study aimed to collect data on healthcare provision for lesbian women in Germany and help to improve the latter. By clicking a verification button, women expressed their informed consent and were able to access the questionnaire. In the paper-based sample, women were informed about the study by a leaflet that contained the same study information offered online and were asked to complete the questionnaire after giving their verbal informed consent. In both conditions they were told that they could refrain from the study without any negative consequences.

Received: 8 June 2016 Accepted: 14 November 2016

Published online: 21 November 2016

\section{References}

1. Addis S, Davies M, Greene G, Macbride-Stewart S, Shepherd M. The health social care and housing needs of lesbian, gay, bisexual and transgender older people: a review of the literature. Health Soc Care Community. 2009; 17(6):647-58.

2. Diamant AL, Wold C, Spritzer K, Gelberg L. Health behaviors, health status, and access to and use of health care: a population-based study of lesbian bisexual, and heterosexual women. Arch Fam Med. 2000:9(10):1043-51.

3. Matthews AK, Brandenburg DL, Johnson TP, Hughes TL. Correlates of underutilization of gynecological cancer screening among lesbian and heterosexual women. Prev Med. 2004;38(1):105-13.

4. Allen O Lesbian, Gay \& Bisexual Patients: The Issues for General Practice. Dublin: Irish College of General Practitioners; 2008.
5. Kerr DL, Santurri L, Peters P. A comparison of lesbian, bisexual, and heterosexual college undergraduate women on selected mental health issues. J Am Coll Health. 2013;61(4):185-94.

6. Austin EL, Irwin JA. Health behaviors and health care utilization of southern lesbians. Womens Health Issues. 2010;20(3):178-84.

7. Sandfort TG, Bakker F, Schellevis FG, Vanwesenbeeck I. Sexual orientation and mental and physical health status: findings from a Dutch population survey. Am J Public Health. 2006;96(6):1119-25.

8. Koh AS, Ross LK. Mental health issues: a comparison of lesbian, bisexual and heterosexual women. J Homosex. 2006;51(1):33-57.

9. Polek CA, Hardie TL, Crowley EM. Lesbians' disclosure of sexual orientation and satisfaction with care. J Transcult Nurs. 2008;19(3):243-9.

10. Steele LS, Tinmouth JM, Lu A. Regular health care use by lesbians: a path analysis of predictive factors. Fam Pract. 2006;23(6):631-6

11. Law M, Mathai A, Veinot $P$, Webster F, Mylopoulos M. Exploring lesbian, gay, bisexual, and queer ( $L G B Q$ ) people's experiences with disclosure of sexual identity to primary care physicians: a qualitative study. BMC Fam Pract. 2015:16:175.

12. Committee on Health Care for Underserved Women. Health Care for Lesbians and Bisexual Women. Obstet Gynecol. 2012;119(5):1077-80.

13. Davy Z, Siriwardena AN. To be or not to be LGBT in primary health care: health care for lesbian, gay, bisexual, and transgender people. $\mathrm{Br}$ । Gen Pract. 2012;62(602):491-2.

14. McKay B. Lesbian, Gay, Bisexual, and Transgender Health Issues, Disparities, and Information Resources. Med Ref Serv Q. 2012;30(4):393-401.

15. Reygan FC, D'Alton P. A pilot training programme for health and social care professionals providing oncological and palliative care to lesbian, gay and bisexual patients in Ireland. Psychooncology. 2012;22(5):1050-4.

16. Rutherford K, Mclntyre J, Daley A, Ross LE. Development of expertise in mental health service provision for lesbian, gay, bisexual and transgender communities. Med Educ. 2012:46(9):903-13.

17. Stott DB. The training needs of general practitioners in the exploration of sexual health matters and providing sexual healthcare to lesbian, gay and bisexual patients. Med Teach. 2013;35(9):752-9.

18. Smith R. Healthcare experiences of lesbian and bisexual women in Cape Town, South Africa. Cult Health Sex. 2015;17(2):180-93.

19. Marques AM, Nogueira C, de Oliveira JM. Lesbians on Medical Encounters: Tales of Heteronormativity, Deception, and Expectations. Health Care Women Int. 2015:36(9):988-1006.

20. Dannecker M. Die Rechtsstellung gleichgeschlechtlicher Lebensgemeinschaften [Legal position of same-sex partnerships]. In: Basedow J, Dopffel K, Kötz H, editors. Sexualwissenschaftliches Gutachten zur Homosexualität [Sexological expertise regarding homosexuality]. Tübingen: Mohr Siebeck; 2000. p. 335-48.

21. Kroenke K, Spitzer RL, Williams JB. The Patient Health Questionnaire-2: Validity of a two-item depression screener. Med Care. 2003;41(11):1284-92.

22. Lowe B, Kroenke K, Grafe K. Detecting and monitoring depression with a two-item questionnaire (PHQ-2). J Psychosom Res. 2005;58(2):163-71.

23. Welch S, Collings SC, Howden-Chapman P. Lesbians in New Zealand: their mental health and satisfaction with mental health services. Aust N Z J Psychiatry. 2000:34(2):256-63.

24. Weisz VK. Social justice considerations for lesbian and bisexual women's health care. J Obstet Gynecol Neonatal Nurs. 2009;38(1):81-7.

25. Warner J, McKeown E, Griffin M, Johnson K, Ramsay A, Cort C, King M. Rates and predictors of mental illness in gay men, lesbians and bisexual men and women: Results from a survey based in England and Wales. Br J Psychiatry. 2004;185:479-85.

26. Bjorkman M, Malterud K. Lesbian women's experiences with health care: a qualitative study. Scand J Prim Health Care. 2009;27(4):238-43.

27. Mravcak SA. Primary care for lesbians and bisexual women. Am Fam Physician. 2006;74(2):279-86

28. Schendera C. Regressionsanalyse mit SPSS [Regression analysis with SPSS]. Munich: Oldenbourg; 2008

29. Tabachnick BG, Fidell LS. Using Multivariate Statistics. Boston: Pearson; 2007.

30. Hirsch O, Löltgen K, Becker A. Comparing health survey data from Internetand paper-based convenience samples of lesbian women in Germany. Sex Health. 2014;11(4):351-8

31. Meyer $\mathbb{H}$. Prejudice, social stress, and mental health in lesbian, gay, and bisexual populations: Conceptual issues and research evidence. Psychol Bull. 2003:129(5):674-97.

32. Kerker BD, Mostashari F, Thorpe L. Health Care Access and Utilization among Women Who Have Sex with Women: Sexual Behavior and Identity. J Urban Health. 2006;83(5):970-9. 
33. Bowen DJ, Bradford JB, Powers D, McMorrow P, Linde R, Murphy BC, Han J, Ellis J. Comparing women of differing sexual orientations using populationbased sampling. Women Health. 2004;40(3):19-34.

34. Mathieson CM, Bailey N, Gurevich M. Health care services for lesbian and bisexual women: some Canadian data. Health Care Women Int. 2002;23(2): 185-96.

35. Durso LE, Meyer $\mathbb{H}$. Patterns and Predictors of Disclosure of Sexual Orientation to Healthcare Providers among Lesbians, Gay Men, and Bisexuals. Sex Res Social Policy. 2013;10(1):35-42.

36. Dennert G, Wolf G. Gesundheit lesbischer und bisexueller Frauen. Zugangsbarrieren im Versorgungssystem als gesundheitspolitische Herausforderung [Health status of lesbian and bisexual women. Barriers to healthcare access as a challenge to health policy]. Femina Politica. 2009;1: 48-59.

37. Dennert G. Die gesundheitliche Situation lesbischer Frauen in Deutschland [Health issues in lesbian women in Germany]. Herbolzheim: Centaurus; 2005.

38. St. Pierre M. Under What Conditions do Lesbians Disclose Their Sexual Orientation to Primary Healthcare Providers? A Review of the Literature. J Lesbian Stud. 2012;16:199-219.

39. Roberts SJ, Patsdaughter CA, Grindel CG, Tarmina MS. Health related behaviors and cancer screening of lesbians: results of the Boston Lesbian Health Project II. Women Health. 2004:39(4):41-55.

40. European Union Agency for Fundamental Rights. European Union lesbian, gay, bisexual and transgender survey. Luxemburg: Publications Office of the European Union; 2013

41. Committee opinion. Health care for lesbians and bisexual women. [http:// www.acog.org/Resources-And-Publications/Committee-Opinions/Committeeon-Health-Care-for-Underserved-Women/Health-Care-for-Lesbians-andBisexual-Women?IsMobileSet=false]

42. Razzano LA, Cook JA, Hamilton MM, Hughes TL, Matthews AK. Predictors of mental health services use among lesbian and heterosexual women. Psychiatr Rehabil J. 2006;29(4):289-98.

43. Kerr DL, Ding K, Thompson AJ. A comparison of lesbian, bisexual, and heterosexual female college undergraduate students on selected reproductive health screenings and sexual behaviors. Womens Health Issues. 2013;23(6):e347-355

44. Mathy RM, Schillace M, Coleman SM, Berquist BE. Methodological rigor with internet samples: New ways to reach underrepresented populations. Cyberpsychol Behav. 2002;5(3):253-66.

45. Sanchez DT, Moss-Racusin CA, Phelan JE, Crocker J. Relationship contingency and sexual motivation in women: Implications for sexual satisfaction. Arch Sex Behav. 2011;40(1):99-110.

46. Malterud K, Bjorkman M, Flatval M, Ohnstad A, Thesen J, Rortveit G. Epidemiological research on marginalized groups implies major validity challenges; Lesbian health as an example. J Clin Epidemiol. 2009;62(7):703-10.

47. Institute of Medicine (US) Committee on Lesbian G, Bisexual, and Transgender Health Issues and Research Gaps and Opportunities. The Health of Lesbian, Gay, Bisexual, and Transgender People. Building a Foundation for Better Understanding. Washington: The National Academies Press; 2011.

48. Dannetun E, Tegnell A, Giesecke J. Parents' attitudes towards hepatitis B vaccination for their children. A survey comparing paper and web questionnaires, Sweden 2005. BMC Public Health. 2007;7:86

49. Warnecke RB, Sudman S, Johnson TP, O'Rourke D, Davis AM, Jobe JB. Cognitive aspects of recalling and reporting health-related events: Papanicolaou smears, clinical breast examinations, and mammograms. Am J Epidemiol. 1997;146(11):982-92.

\section{Submit your next manuscript to BioMed Central and we will help you at every step:}

- We accept pre-submission inquiries

- Our selector tool helps you to find the most relevant journal

- We provide round the clock customer support

- Convenient online submission

- Thorough peer review

- Inclusion in PubMed and all major indexing services

- Maximum visibility for your research

Submit your manuscript at www.biomedcentral.com/submit
Biomed Central 